Family Profile No. 26, 2018

\title{
Young Adults Living Alone, with Siblings, or with Roommates
}

\section{Author: Valerie J. Schweizer \& Krista K. Payne}

Young adults live in a range of circumstances including a large proportion who live with their parents (FP-16-16) or are living with cohabiting partners or spouses (FP-16-17). Less attention has been paid to single young adults who live outside their parent's home, live alone, or live with either siblings or roommates. Using data from the 1990 U.S. Census and the 2016 American Community Survey, this profile focuses on young adults aged 18 to 29 living alone or with a sibling or roommate. Young adults living with a sibling and a roommate are included in the living with a sibling category and not in the living with a roommate category. For information on older adults living with siblings and roommates, see the profile "Living with a Sibling or Roommate in Older Adulthood, 1990 \& 2016" (FP-18-19).

Young Adult's Living Arrangement, 1990 \& 2016

- The number of single young adults living with siblings or roommates has increased over time. In 1990, approximately 5.3 million young adults were living with a sibling or roommate. In 2016, the number rose to 6.7 million.

- While the share of single young adults living alone or with siblings has not changed, a slight increase occurred in the share of young adults living with roommates-from $7 \%$ in 1990 to $9 \%$ in 2016. About one in five is single and not living with their parents.
Figure 1. Young Adults Living Alone or with a Sibling or Roommate, 1990 \& 2016

n Living Alone $n$ Living with a Sibling $\square$ Living with a Roommate

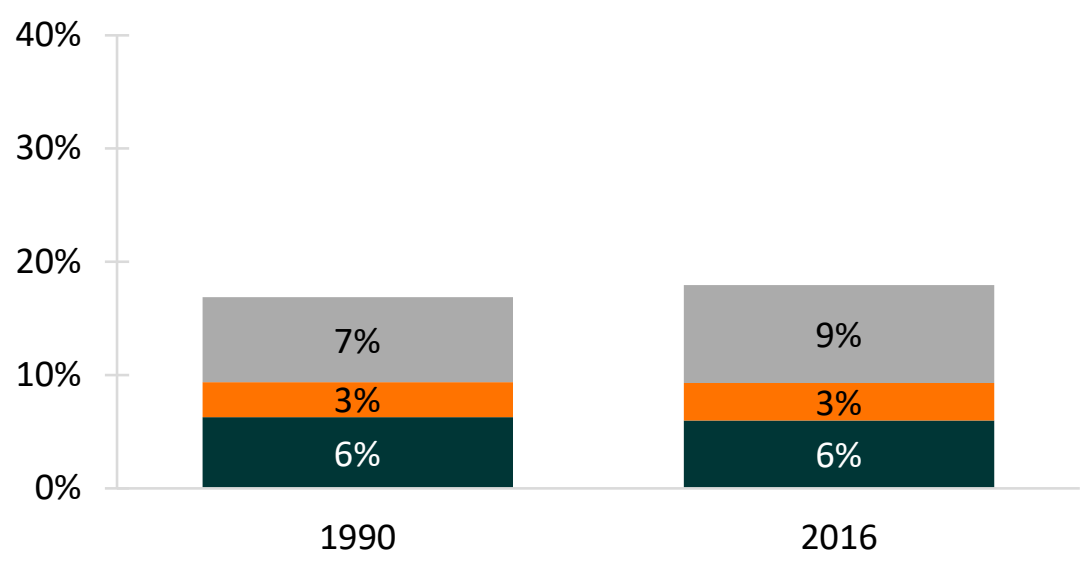

Source: NCFMR analyses of U.S. Census Bureau, Decennial Census, 1990; U.S. Census Bureau, American Community Survey, 2016 (IPUMS

Young Adult's Living Arrangement, by Age and Gender, 2016

- Among single young adults not living with a parent, most of those aged 18 to 24 years are living with a roommate. This pattern shifts for those aged 25 to 29, with about two in five living with a roommate and two in five living alone.

- Patterns do not appreciably differ between men and women for either age group.

- Regardless of age or gender, about one in five young adults who is single and not living with a parent live with a sibling.
Figure 2. Young Adults Living Alone or with a Sibling or Roommate, by Age and Gender, 2016

- Living Alone $\square$ Living with a Sibling $\square$ Living with a Roommate

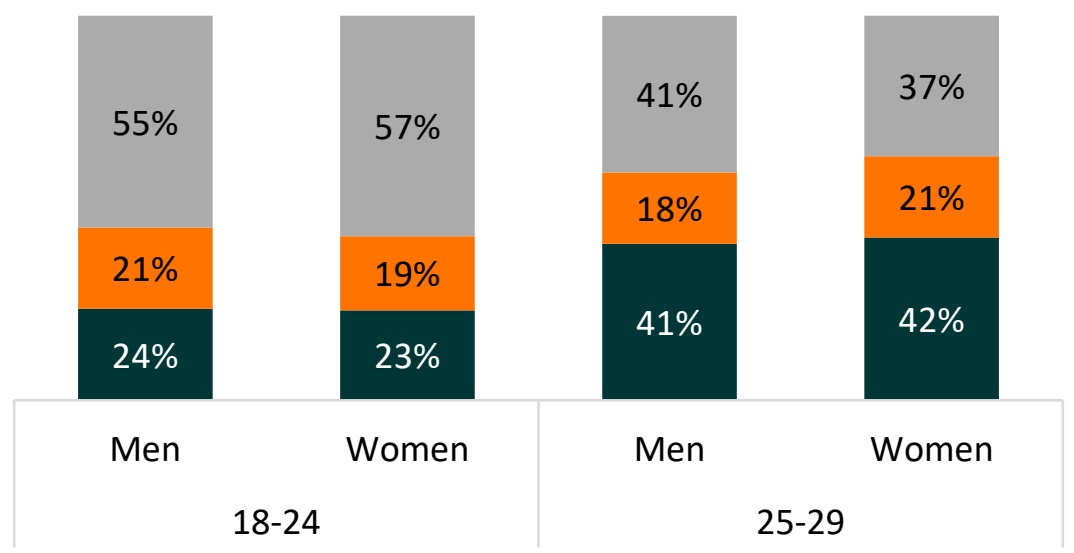

Source: NCFMR analyses of U.S. Census Bureau, American Community Survey, 2016 (IPUMS) 
- Among singles aged 25 to 29 years not living with a parent, there is an education gradient in the share living with a sibling and on their own. Only one in ten college graduates live with a sibling and $42 \%$ of single young adults without a high school degree live with a sibling. Approaching one half $(47 \%)$ of college graduates live alone, and only onequarter without a high school degree live on their own.

- Nearly one in seven Blacks experienced a cohabitation, a birth, and a marriage during young adulthood, compared to nearly one in four Hispanics (23\%) and Whites (25\%).
Figure 3. Young Adults Aged 25 to 29 Living Alone or with a Sibling or Roommate, by Education, 2016

Living Alone $\square$ Living with a Sibling $\square$ Living with a Roommate

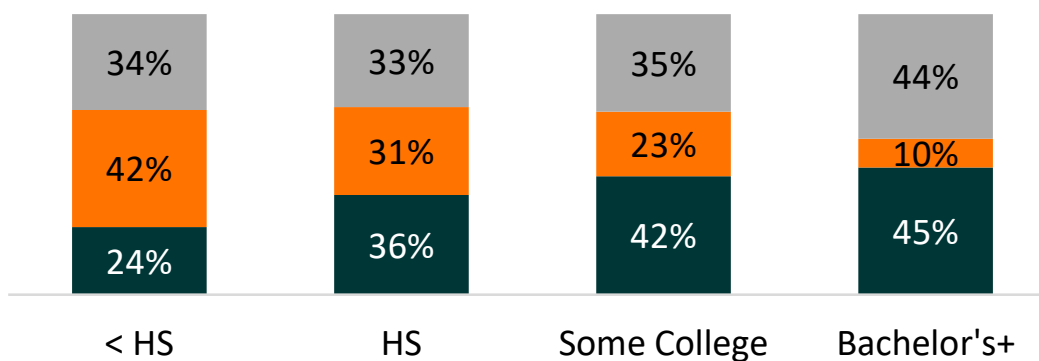

Source: NCFMR analyses of U.S. Census Bureau, American Community Survey, 2016 (IPUMS)

Note: A large majority of those aged 18 to 24 years have not yet completed their schooling, therefore we limit these analyses to those aged 25 to 29 .

\section{Young Adult's Living Arrangement, by Age and Race/Ethnicity, 2016}

- There are striking differentials in living arrangements by race and ethnicity. In each age group, Blacks more often live alone than the other groups considered here. Half (53\%) of single Black older young adults not living with their parents live alone.

- There is little variation by age among young adults who live with siblings across race/ethnicity. Hispanics have the largest share living with siblings among both young adults aged 18 to 24 years (44\%) and 25 to 29 (40\%). Among foreign-born Hispanics (not shown), the shares are even larger with $56 \%$ of foreign-born Hispanics aged 18 to 24 years and half of those aged 25 to 29 living with siblings.

- Across race/ethnicity, those aged 18 to 24 have a larger share of young adults living with roommates than those aged 25 to 29. Asians have the largest share living with roommates regardless of age $-65 \%$ of single Asians aged 18 to 24 years and $46 \%$ among those aged 25 to 29 .
Figure 4. Young Adults Living Alone or with a Sibling or Roommate, by Age and Race/Ethnicity, 2016

Living Alone $n$ Living with a Sibling $n$ Living with a Roommate

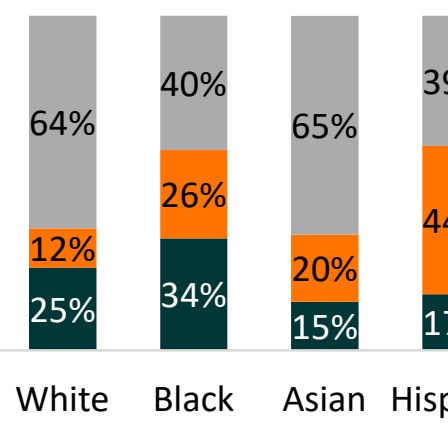

$18-24$

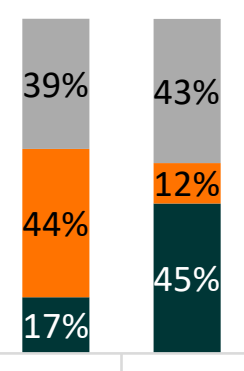

Hispanic White

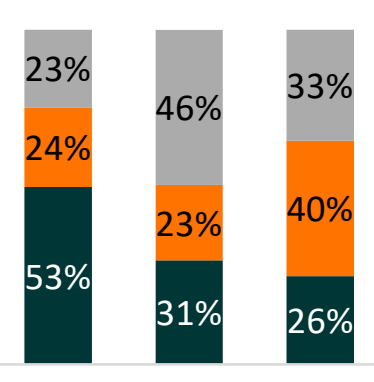

Black Asian Hispanic
$25-29$

Source: NCFMR analyses of U.S. Census Bureau, American Community Survey, 2016 (IPUMS)

Data Source:

Ruggles, S., Flood, S., Goeken, R., Grover, J., Meyer, E., Pacas, J., \& Sobek, M. IPUMS USA: Version 8.0 [dataset]. Minneapolis, MN: IPUMS, 2018. https://doi.org/10.18128/D010.V8.0

References:

Lamidi, E. \& Manning, W. D. (2016). Marriage and cohabitation experiences among young adults. Family Profiles, FP-16-17. Bowling Green, OH: National Center for Family \& Marriage Research. https://www.bgsu.edu/ncfmr/resources/data/family-profiles/lamidi-manning-marriagecohabitation-young-adults-fp-16-17.html

Payne, K. K. (2016). Young adults in the parental home, 2007-2015. Family Profiles, FP-16-16. Bowling Green, $\mathrm{OH}$ : National Center for Family \& Marriage Research.

https://www.bgsu.edu/ncfmr/resources/data/family-profiles/payne-young-adults-parentalhome-2007-2015-fp-16-16.html

Wu, H. (2018). Living with a sibling or roommate in older adulthood, 1990 \& 2016. Family Profiles, FP-18-19. Bowling Green, $\mathrm{OH}$ : National Center for Family \& Marriage Research. https://doi.org/10.25035/ncfmr/fp-18-19

\section{Suggested Citation:}

Schweizer, V. \& Payne K. K. (2018). Young adults living alone, with siblings, or with roommates. Family Profiles, FP-18-26. Bowling Green, OH: National Center for Family \& Marriage Research. https://doi.org/10.25035/ncfmr/fp-18-26

\begin{tabular}{|c|c|}
\hline \begin{tabular}{l|l} 
:CSU. & $\begin{array}{l}\text { National Center for } \\
\text { Family \& Marriage Research }\end{array}$
\end{tabular} & $\begin{array}{l}\text { http://www.bgsu.edu/ncfmr } \\
\text { ncfmr@bgsu.edu }\end{array}$ \\
\hline BOWLING GREEN STATE UNIVERSITY & (419) 372-3119 \\
\hline
\end{tabular}

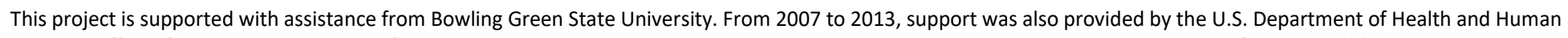

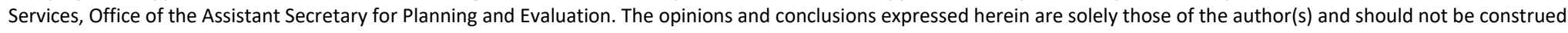
as representing the opinions or policy of any agency of the state or federal government. 